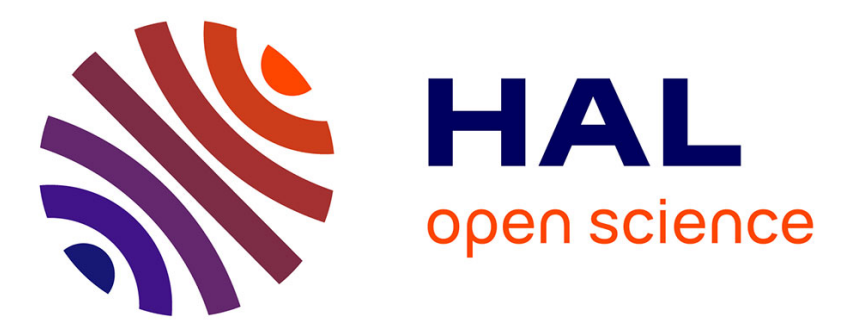

\title{
Le mal subi, le mal rendu. Une lecture anthropologique des pratiques de lamentations et de malédictions dans le shicisme populaire iranien
}

Sepideh Parsapajouh

\section{- To cite this version:}

Sepideh Parsapajouh. Le mal subi, le mal rendu. Une lecture anthropologique des pratiques de lamentations et de malédictions dans le shicisme populaire iranien. Oriens, 2021, 49 (3-4), pp.370-397. 10.1163/18778372-12340005 . hal-03503361

\section{HAL Id: hal-03503361 \\ https://hal.science/hal-03503361}

Submitted on 4 Jan 2022

HAL is a multi-disciplinary open access archive for the deposit and dissemination of scientific research documents, whether they are published or not. The documents may come from teaching and research institutions in France or abroad, or from public or private research centers.
L'archive ouverte pluridisciplinaire HAL, est destinée au dépôt et à la diffusion de documents scientifiques de niveau recherche, publiés ou non, émanant des établissements d'enseignement et de recherche français ou étrangers, des laboratoires publics ou privés. 


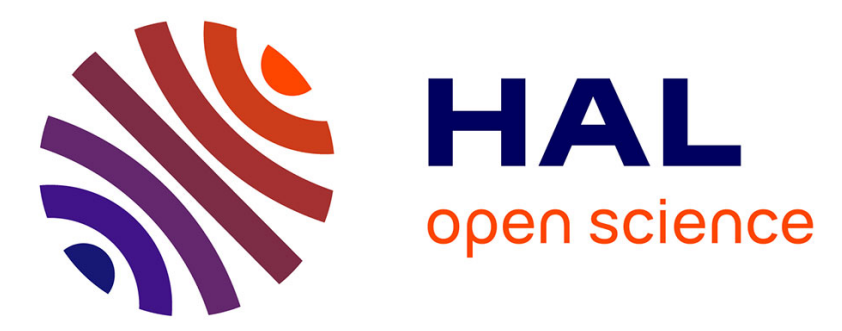

\section{Le mal subi, le mal rendu. Une lecture anthropologique des pratiques de lamentations et de malédictions dans le shicisme populaire iranien}

Sepideh Parsapajouh

\section{- To cite this version:}

Sepideh Parsapajouh. Le mal subi, le mal rendu. Une lecture anthropologique des pratiques de lamentations et de malédictions dans le shicisme populaire iranien. Oriens, Brill Academic Publishers, 2021, 49 (3-4), pp.370-397. 10.1163/18778372-12340005 . hal-03503361

\section{HAL Id: hal-03503361 \\ https://hal.archives-ouvertes.fr/hal-03503361}

Submitted on 4 Jan 2022

HAL is a multi-disciplinary open access archive for the deposit and dissemination of scientific research documents, whether they are published or not. The documents may come from teaching and research institutions in France or abroad, or from public or private research centers.
L'archive ouverte pluridisciplinaire HAL, est destinée au dépôt et à la diffusion de documents scientifiques de niveau recherche, publiés ou non, émanant des établissements d'enseignement et de recherche français ou étrangers, des laboratoires publics ou privés. 


\section{Le mal subi, le mal rendu. Une lecture anthropologique des pratiques de lamentations et de malédictions dans le shi isme populaire iranien}

Sepideh Parsapajouh

ORCID: 0000-0002-3202-386X CNRS, CéSor, Paris, France

sepideh.parsapajouh@gmail.com

\section{Résumé}

Dans le shi isme duodécimain iranien, deux catégories de traditions populaires (com- prenantrituels,pratiqueset croyances) ontprisformeaucoursdutempsautourdela question du mal, précisément des souffrances et de la mort subies par les personnes de la famille du Prophète (ablal-bayt). La première catégorie comprend les expressions poétiquesélégiaques (martĩya) accompagnées de pratiques reflétantlapassionetla compassionpourles victimes de la mort injuste, à commencer par le troisième imam Ḥusayn. La seconde catégorie comprend de violentes expressions satiriques de malé- diction adressées aux auteurs de ce mal. Cette tradition mobilise aussi la récitation de prières et de formules dévotionnelles tirées du corpus scripturaire sacré, ainsi qu'un ensemble de pratiques particulières appelées 'Umar-košr ( le meurtre de 'Umar »). Cet article propose d'analyser la formation et la fonctiondeces deuxtraditions, ainsique l'évolutiondeleurformeetdeleursignificationdanslecontextesocialdu shi isme ira- nien contemporain. Il montrera que ces deux traditions, tout en étant cohérentes avec le double principe shi ite de tawallä (loyauté et amour pour les imams) et tabarrà (dissociation et haine à l'égard de leurs adversaires), reflètent clairement l'autonomie des croyants vis-à-vis du pouvoir politique comme de l'autorité religieuse institutionnelle.

\section{Mots-clés}

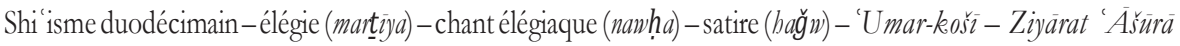
- religion populaire 


\begin{abstract}
In Iranian Twelver Shi' ism, two categories of popular traditions (including rituals, practices and beliefs) have taken shape over time around the issue of evil, namely the harm and death suffered by the holy figures of the house of the Prophet (ablal-bayt). The first category includes elegiac poetic expressions (martiya), accompanied by ritual practices reflecting passion and compassion for the victims of unjust death - notably the third imam, Husayn. The second category includes violent and satirical expressions of maledictions, addressed to the authors of this evil. This tradition also involves the recitation of prayers and devotional formulas borrowed from the sacred scriptural corpus as well as particularpractices called 'Umar-kosì (the murder of 'Umar). This article offers an analysis of the formation and function of these two traditions, as well as the development of their form and meaning in the social context of contemporary IranianShi' ism. Itshowsthat, bybeinginlinewiththedouble Shi i principle of tawalla (loyalty and love towards the Imams) and tabarra (dissociation and hatred towards the enemies of the Imams), these twotraditions clearly reflectthe autonomy of the believers vis-à-vis both political powerand institutional religious authority.
\end{abstract}

\title{
Keywords
}

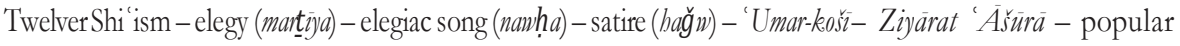
religion

Auseindushi ismeiraniend'obédienceimamiteouduodécimaine, deuxcatégories de traditions populaires, ensembles de rituels, de pratiques et de croyances, ont pris forme au cours du temps autour de la notion de mal, ce dernier représenté par les souffrances historiques des membres de la «Sainte Famille du Prophète » (ablal-bayt) et leurs auteurs. La première catégorie de traditions com- prend les expressions littéraires du genre élégiaque nommé de l'arabe martīya (aussi ritāa), qui ne sont pas sans évoquer le chœur d'une tragédie grecque. Ces récitations sontaccompagnées de pratiques rituelles exprimantla com- passion - au sens étymologique de la passion éprouvée avec et à la place de quelqu'un - pour les personnes sacrées victimes de la mort injuste. Ces per- sonnes sont d'abord 'Alī, le premier imam, Fātịma, son épouse et la fille du Prophète, etplus encore Husayn, letroisièmeimam, appelé « leseigneurdes martyrs» (sayyid al-šrubadä), et les compagnons de ce dernier. La seconde catégorie de traditions rassemble des expressions orales violentes et satiriques, principalement sous forme de malédictions, àl'adresse des auteurs decette 
mort injuste. Accompagné aussi par la récitation d'un ensemble de prières et de formules pieuses puisées dans le corpus scripturaire sacré (Coran et Hadit), il s'agit du rituel particulier nommé 'Umarkoš̌, dédié au meurtrede 'Umarb. al-Hुaț̣āb(m.23/644), letroisième«califebienguidé»des sunniteset l'adversaire historique de 'Alī. Bien que des précédents de ces deux traditions peuvent être trouvés en Iran préislamique, toutes deux s'inscrivent clairement dans la doctrine shi ite imamite à travers le double principe de tanwalà (le devoir d'aimer les imams et leursamis) et tabbarä (le devoir de haïr les ennemis des imams). Au cours del'histoire, ces croyances et pratiques ontconnu, selonles conditions sociopolitiques, des phases successives et cycliques de discrétion et d'excès, de dissimulation et d'exhibition; ellessontdemeurées très vivaces jusqu'à aujourd'hui parmi certains groupes de shi 'ites iraniens, en dépit des contraintes posées par les lois politiques et les positions de l'«orthodoxie» officielle.

Après un bref historique de la formation de ces deux traditions, nous ana- lyserons le développement de ces croyances et pratiques, dans leur forme extérieure et leur signification interne, en relationavecles normesetinjonctions des autorités religieuses et politiques, dans la société shi ite iranienne contemporain. Les données de cette étude, outre des documents historiques, sont issues des recherches de terrain, d'observations et d'entretiens réalisés dans les villes de Téhéran et de Qomentre2014 et 2016.

\section{I}

La première tradition populaire s'est formée autour du genre poétique de l'élégie, appelé marțȳa, employé particulièrement pour exprimerla compassion avecles souffrances, les douleurs etles maux subis par les abl al-bayt, principalement 'Alī, Fāțima et les imams de leur descendance. De ces souffrances témoignent abondamment les sources shi ites, y compris des textes transmis des imams ayant pris pour les shi' ites une valeur sacrée.

Dans les Prairies dor (Muriğgl-dabab) de l'historien iranien et shi ite al-Mas'ūdì (m. 345/956), on peut lire que l'élégie est le plus ancien genre poétique et que la première élégie, rapportée en arabe, aurait été l'œuvre d'Adam, déclarée au sujet de son fils Abel assassiné par son frère Caïnl. Selon des données historiques plus crédibles, le genre poétique du rițä ou martĩya, est attesté dans la poésie arabe préislamique. Il s'agit d'un poème funèbre pleurant

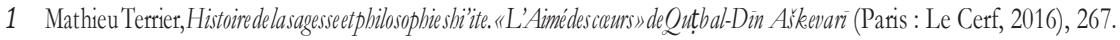


la mort ou l'absence d'un être aimé, parfois la destruction d'un campement ou d'une ville. La poésie arabe préislamique n'a été mise à l'écrit quà l'époque omeyyade, de laquelle date aussi l'élégie attribuée à Adam. En Perse ancienne, une forme d'élégie appelée sūg-sarajyī, semble avoir été courante, liée à la commémoration de figures mythiques tenues pour des victimes exemplaires, comme Sìyāvaš (on parle

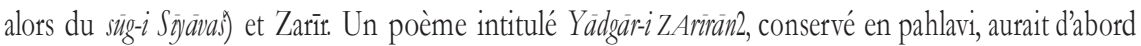
existé en langue parthe. C'est en milieu shi ite, au sujet des imams et du troisième, Husayn, en particulier, que le martìya commence à apparaitre comme une expression collective. Rappelons que le second petit-fils du Prophète, al-Husayn, fut mis à mort sans pitié, avec soixante-douze de ses compagnons et familiers (un chiffre fixé par la Tradition), après dix jours d'encerclement et de privation d'eau, par les troupes de l'armée omeyyade du calife Yazìd ler, sur la plaine de Karbala, le 9 et le 10 (Tasū à et 'Ašūrāa du mois de Muharrram de l'an 61 de l'hé- gire (9 et 10 octobre 680). Les shi' ites de toutes obédiences ont toujours voué une affection très vive à cet imam, et les imamites n'ont cessé de commémo- rer passionnément ses souffrances et celles des siens à Karbala. L'histoire du martĩya est elle-même réécrite par la foi et se fait légende: selon des récits shi ites, le martyre de limam Ḥusayn aurait été connu et pleuré par avance par le prophète Muhammad3, averti par l’ange Gabriel, et limam 'Alī aurait com- posé les premières élégies pour son fils Ḥusayn tué vingt ans après lui. Voici un passage de la poésie attribuée à l'imam 'Alīis:

Commesijeregardaismesenfantsetmoi-même Leschamps de

Karbala et de la bataille

Où nos barbes seraient teintes de sang Commedes

tenuesbarioléesdelamariée

On peut tenir pour plus probable le rapport du traditionniste shi ìte 'Alī Ibn Ṭāwūs(m. 664/1266), auteurdelapremièrechroniquedudramede Karbala,

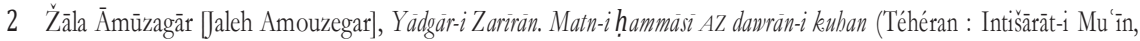
1393 Š/2014), texte pehlevi, traduction et commentaire en per- san; à ce sujet voir aussi 'Abbās Azarandāz, «Yādgār-i

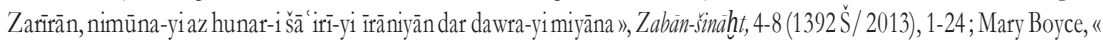
Yādgăar-e Zarî̀ān», Encyclopadia Iranica,III.2, 128-129.

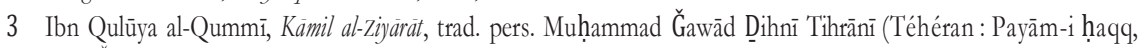
1377 Š/1998), 344 .

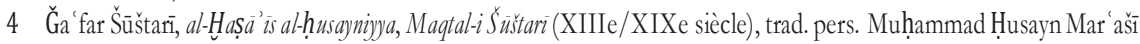

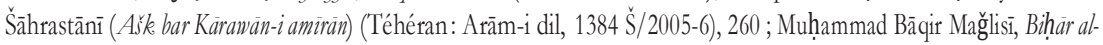
anwär(Téhéran: Maṭba at al-'Alawī, 1364 Š/1985), vol. 44, 267. 


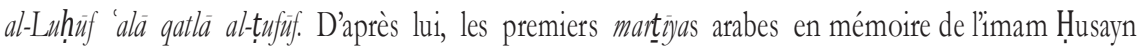
dateraient du jour même de sa mort et auraient pour auteurs des rescapés du drame: 'Alī b. al-Husayn (m. ca 95/714), le quatrième imam, et deux sœurs de limam Ḥusayn, Umm Kultūim et Zaynab. Ibn Țâwūs écrit à ce propos:

Zaynab se présenta auprès des corps purs des martyrs. Elle commença à réciter des martîyas de manière si douloureuse que les ennemis comme les amis en pleurèrent. [Lui est attribué ce poème:]

Ô Muḥammad! Voilà ton Ḥusayn maculé de sang [...]

Ô Muhammad! Voilà ton Husayn tombé sur la terre de Karbala Quele vent de Saba

(Zéphyr) saupoudre de poussière $[\ldots]^{5}$

Au cours du temps, la tragédie de limam Hịsayn s'est chargée de nombreuses significations: le «sacrifice de soi» du guide spirituel qui, sans réel espoir de victoire, aurait revivifié l'islam en dévoilant les identités de ses dirigeants corrompus, usurpateurs du califat légitime; un sacrifice sacré absolument inimitable - selon l'exégèse imamite, Husayn serait la "prestigieuse victime» (dibhh-i azìim) évoquée dans le verset coranique 37: 1076, soit la rançon de la vie d'Ismaël'; ou au contraire, à l'époque moderne, un exemple à suivre de refus de l'humiliation, de courage devant la souffrance et de mépris de la mort, un héroïsme résumé dans une formule devenue proverbiale en Iran: «Mieux vaut la mort rouge [sang] que la vie indigne » (marg-i suhth bibtar AZ Zandagi-yi nangin ast). Quoi qu'il en soit des différences d'interprétation, la geste de Husayn unit les shi ites autour de sa mémoire et constitue un motif permanent d'affirmation de la communauté et de son identité. Et pour tous les shi'ites, le meurtre du troisième imam, petit-fils du Prophète, est la plus grave injustice de l'Histoire, le plus grand mal subi par le meilleur des hommes.

Les sources rapportent que 'Alī b. al-Ḥusayn, à son retour à La Mecque après le massacre, demandeà un certain Bašîrb. Hazlam s'il maîtrisela poésie comme sonpère, un célèbrepoète.Comme Bašìr lui répond positivement, l'imam l'envoie à Médine annoncer aux croyants, par une poésie, le martyre

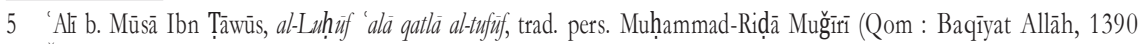
Š/2011), 150 .

6 «Nousle rachetâmes contre une prestigieuse victime»: Le Coran, essai de traduction Jacques Berque (Paris: Albin Michel, 2002), 482.

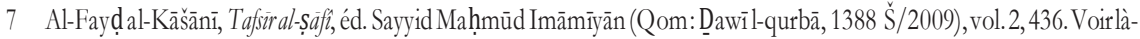
dessus Mathieu Terrier, «Le combat sacré des vaincus de l'his- toire: expérience et représentation du jibäd dans le shi'sisme imamite ancien», Journal Asiatique, 305.1 (2017):23-31, 27. 
de l'imam Ḥusayn et le drame de Karbala. Voici son récit et la poésie qui lui est attribuée8:

J'aicouru, galopant jusqu’à Médine, et dès que j’ai mis le pied dans la mosquée duProphète,jai augmentémavoixdepleursetrécitécettepoésie:

«Ô habitantsde Yatrib" Nerestezplusdanscette ville, Husaynaététué et mes larmes coulent Son corps est maculé de sang à Karbala, et sa tête, on la tourne surune lance».

À partir de l'événement de Karbala, le martīya trouve une place privilégiée parmi les shi ites comme rappel de l'histoire et expression de la mémoire. Dans les recueils de hadits imamites, on trouve que les imams appréciaient, parfois même commandaient et récompensaient des martìya décrivant des douleurs subies par Ḥusayn et ses compagnons ainsi que par d'autres «gens de la famille du Prophète». Par exemple, ce ḥadit attribué au sixième imam, Ğa far al-Sạadiq (m. 148/ 748) ${ }^{10}$ :

«Celui qui chante un martīya pour Husayn et celui dont le martīya fait pleureruneautre personnepourHisayn,auneplaceauparadis ».

Toutefois, le genre semble être apparu assez tardivement en Iran islamisé et en langue persane. Le premier martīya, sous sa forme classique de la qasida arabe ${ }^{11}$, serait l'œuvre d'un certain Abū alYanbaḡi et remonterait au IIIe/ IXe siècle; il aurait eu pour motif la ruine de la ville de Samarkand. Rūdaki (m. 330/941) est considéré commele premiercompositeurde martīya en persan, notamment d'un célèbre poème pour le deuil du poète Šahỉd Balhīi. Mais c'est Kasā̄i Marwazî, poète du IVe/Xe siècle originaire de Merv, qui aurait com- posé le premier marțya en persan pour le deuil de Husayn. Voiciunexemple de ses élégies à propos de Husayn ${ }^{12}$ :

Ton cadavre, je ne sais quel accident il fut,

Qui polit tous les yeux et blessa toutes les âmes

L'eaudesyeuxinondanttoutMervcommeledélugedeNoé Toncadavre

flottantsurcetteeau,toisemblableàunnavire

8 Ibn Țāwūs, al-Luhüf, 150.

9 Le nom de la ville de Médine avant quele Prophète s'y installe.

10 Ibn Qūlūya, Kämilal-ziyàrät,344.

11 Pour la définition, voir plus bas, note 15.

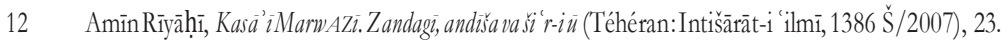


Cette apparition tardive en Iran du martĩya pour Husayn s'explique par la domination sunnite et la répression systématique des nombreux courants shi ites jusqu’à larrivée des vizirs bouyides d’obédience shi ite, originaires du Daylām en Iran, qui régnèrent du milieu du IVe/Xe au milieu du Ve/XIe siècle. Sous leur pouvoir, les shi ites bénéficièrent d'une plus grande liberté d'ex- pression. Lon vit alors apparaître, dans l'espace public des rues et des bazars, les premières cérémonies de deuil pour limam Husayn durant le mois de Muharram, avec des pratiques de lamentation (chants, griffures du visage, etc.) auxquelles participaient aussi les femmes ${ }^{13}$. De cette période, on peut mentionner le célèbre Nāṣir Khustaw Qubādiyānī (m. 481/1074), ismaélien de Badahššn, qui a composé plusieurs poèmes de dévotion aux Imams. À la période mon- gole, on compte plusieurs martīyas en mémoire de Karbala composés par le poète mystique Farīd al-Dīn 'Aț̣ār Nišābūrī (m. 618/1221), ainsi que par le šayh 'Abd al-Raḥmān b. Aḥmad Nūr al-Dīn Ğāmī (m. 898/1492). Mais c'est à partir de 906/1501 et linstauration du shi isme comme religion d'État par Šāh Ismāîl, le premier des Safavides, que la production de martĩyas consacrés au mois de Muharram et au jour de 'Ǎšunrā devient florissante en Iran ${ }^{14}$. Cet épanouisse- ment, encouragé par le pouvoir politique, entraine une évolution du genre que je n’analyserai pas en détails ${ }^{15}$. Mais il importe de préciser que durant cette époque, d’autres formes poétiques viennent progressivement se joindre à la forme jusque-là unique de la qasida comme le tarğ̌i -band, le tarkib-band et le masnawn ${ }^{16}$.

13 Moḥsen Ḥisām-Maẓāhirī, Risāna-yiš̌i a (Téhéran:Šarkatčāpwanašr-ibayn-al-milal,1388 Š/2009), 41-47.

14 À ce propos, notons également que ce fut sous l'ordre de Šāh Ismāi īl, en 914/1508, et suite à sa visite pieuse à Karbala, que le mausolée de l’imam Ḥusayn fut rénové après six siècles, le premier dôme ayantété construit sous les Bouyides en366/976, après la destruction totale des lieux saints sousle calife 'abbassideal-Mutawwakilen236/850.

15 Jusqu'au VIIIe/XIVe siècle, le martiya avait la forme de la qasida arabe, une ode non-strophique monomètre et monorime d'une longueur minimum de quatorze vers (généralement entre cinquante et deux cents), chaque vers représentant une unité de sens indépendante du précédent et du suivant. Appelé en persan šakàma, de šakäa, «la plainte», il s'agissait d'un poème lyrique laudatif composé à l'occasion de fêtes princières. La qasìda persane est organisée en distiques, chaque vers comportant deux hémistiches, avec une rime revenant au dernier hémistiche de chaque distique.

16 Le tarğ $\imath^{\imath}-b a n d$ est un ensemble de $\dot{g} A Z$ als liés par un même distique. Chaque groupe de ġaZals est composé de cinq à vingt-cinq distiques. Le tarkib-band est semblable au tarğ $i$ - band à ceci près que le refrain séparant et reliant les ġAZals est à chaque fois dif- férent. Le matnawi est un poème constitué en distiques ayant chacun sa rime propre. Au sujet de poèmes élégiaques voir aussi Henry Massé, "Poèmes funèbres consacrés aux imâms», dans TouficFahd (éd.), Leshî ismeimâmite (Paris: Presses Universitaires de France, 1970), 271-279. 
Lauteur de marțya le plus important de cette époque est Moḥtašam Kāšānī (m. 996/1588), poète de cour très apprécié par Šāh Tahmāsb (r. 930- 984/1524-1576), surnommé le père du marťìa

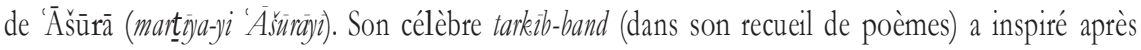
lui de nombreux martìya respectant la même rime et la même métrique l?. Voici son célèbre refrain, maintes fois lu, calligraphié, écrit ou chanté chaque année au sein des cortèges de croyants et pénitents appelés en persan dasta (ou dasteh), qui effectuent les rituels de 'Āšūrāen Iran:

Qu'est-ce encore que cette passion entre les créatures du monde Qu'est-ce encore que ces pleurs, cette peine, cette douleur?

À l'époque des Qàjār (1174-1304/1786-1925), les šăhs manifestent plus encore la dévotion passionnée pour les Imams. Ils encouragent non seulement la poésie dévotionnelle, mais aussi la production d'images des imams comme du Prophète, ainsi que l'art dramatique du ta'ziya. C'est alors qu'un genre nouveau commence à occuper une place importante à côté du marțya classique. Il s'agit du nawha, de forme plus libre et plus légère, composé pour être chanté et accompagner les performances des cérémonies de Muharram, comme les pratiques d'auto-flagellation. Le nawha est fréquemment chanté avant d’être écrit et adapté aux normes littéraires; ses rimes et sa métrique sont choisies pour répondre aux rythmes corporels des performances rituelles18.

Parmi les compositeurs d'élégies pour l'imam Husayn à l'époque qàjār, on peut citer Sabāhị Bīdgulī (XIIIe/XIXe siècle) et Mìrzā Abū al-Ḥasan Yağmà̄i Ǧandaqī (m. 1238/1859), le poète le plus distingué de cette époque, à qui est attribué le premier recueil de nawhas marquant une révolution du genre élégiaque. Voici un exemple de ses élégies 19:

Ôsoleilducieldelareligion, àl'arméeplusnombreusequelesétoiles lumineuses

Les lances dans le palais du sang

Ô soleil, ne retire pas ton épée de la gaine de l'aube

Ô soleil

17 Muhtašam Kāšānī, Diwàn, éd. Akbar Bihdārvand (Téhéran: Intišārāt-i Nigāh, 1392 Š/2013-14).

18 Son message est immédiatement compréhensible, ses phrases sont courtes et facilement mémorisables, dans un lexique simple, dénué de sophistication, ouvert aux changements de termes et aux ajouts.

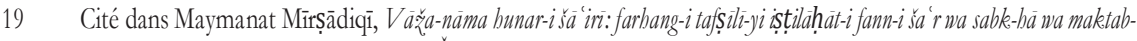
bā-yiān (Téhéran: Kitāb-i Mahnāz, 1389 Š/2010), 288. 
Redresse-toi, ô soleil

La foudre du regret a tué les feuilles et les branches de ces gens endoloris

Tous confondus

Ils ont brûlé les uns dans les autres

Toi, soleil,nemetspas plusdefeudansleurblé

Ô soleil

Redresse-toi une fois encore, soleil

À cette époque, les rituels de deuil et la pratique poétique qui les accompagne se popularisent ${ }^{20}$. Les pièces poétiques sont composées par des gens de plus en plus simples, issus de milieux plus accoutumés à l'expression orale qu'à la littérature. Le martíya sort des plumes des poètes de cour professionnels pour se changer en nawha dans les bouches des chantres populaires. Des membres du clergé shi ite ne tardent pas à réagir contre certaines pratiques effectuées et paroles prononcées lors des cérémonies du mois de Muharram, jugeant qu'elles relèvent de l'exagération (julüw), terme désignant chez les théolo- giens imamites une hétérodoxie et une hétéropraxie internes au shi'isme, qu'il convient de réfuter et de réprimer.

La fin de la période Qàjār marque le début d'une nouvelle phase de politi- sation du religieux, avec les mouvements sociopolitiques liés à la révolution constitutionnelle (1905-1911) et l'engagement du clergé dans ce mouvement. Les propos politiques commencent à sintroduire dans les élégies de 'Āshūrā. On assiste à l'apparition d'une forme de martĩya national. La lamentation, jusque-là expression d'une dévotion et d'un ritualisme quiétiste, se mue en hymne activiste ayant pour but de réveiller le peuple et de le «conscientiser». Ce changement se poursuit de manière plus accentuée à l'époque des rois

20 Ces martìias étaient alors nommés également: $\sin$-ZAnì (sina = poitrine, ZAni = l'acte de frapper) ou sang-ZAni (sang $=$ pierre). Or ces termes se référent plutôt aux actes et aux performances rituels qu'aux expressions orales ou écrites de la poésie. Au sujet de ces performances, de nombreux travaux ont été publiés, parmi lesquels Jean Calmard,

«Shi' i Rituals and Power II. The Consolidation of Safavid Shi ism: Folklore and Popular Religion», dans Charles Melville (éd.), Safavid Persia (London-New York: Pembroke Papers, 1996), 139-190; Christian Bromberger, " Martyre, deuil et remords: horizons mythiques et rituels des religions méditerranéennes (à propos des 'passions' du Christ et de l'Imam Husayn: essai d'analyse comparée) », Études corres 12:13 (1979): La mort en Corse et dans les societés méditerranéennes, 129-153; Kamran Scott Aghaie, The Martyrs of Karbala. Shiii Symbols and Rituals in Modern Iran (Seattle: University of Washington Press, 2004); Sabrina Mervin, «Les larmes et le sang des shi ites: corps et pratiques rituelles lors des célébrations de 'Âshûrâ' (Liban, Syrie) ), Revue des mondes musulmans et de la Méditerraneée (REMMM), 113-114 (2006), 153-156; Sepideh Parsapajouh, Auccurd dun bidonville iranien (Paris: Karthala-IFRI, 2016), 267-310. 
(šăhs) Pahlavi, notamment sous le règne de Pahlavi II, dans les mouvements ayant abouti à la révolution islamique de 1979. Je n'entrerai pas ici dans le détail des nombreuses tensions entre le pouvoir politique, la religion institutionnelle desclercsetlareligiosité populaireau cours decettepériode. Maisil est intéressant de noter que dans les discours et les slogans, la répression royale des mouvements cléricaux et des révoltes populaires est de plus en plus assimilée à l’injustice absolue de Karbala, un amalgame fait notamment par l'ayatollah Khomeiny. Il faut aussi rappeler la cristallisation des tensions autour des cérémonies du mois de Muharram 1963, quand le régime du Šāh interdit les pratiques qualifiées d'exagérées et demanda expressément aux religieux de ne pas tenir des propos politiques dans leur discours ${ }^{21}$. En réponse, l'ayatollah Khomeiny appelales clercs de touteslesvillesà transgresserles ordres et encouragea l'insertion de propos politiques dans les naw has chantéslors des cérémonies ${ }^{22}$. Voici l'exemple de ce que Sāàdiq Amānī a chanté alors au sein des bay at (les locaux des groupes cérémoniels) dans les années 1340/196023:

Lebien aimé deFāṭima [Ḥusayn] dit : je n’ai pas peurde lamort Je ne me soumettrai pas à l'oppression tant qu'une âme habitera mon corps Lahonte et la bassesse de la vie, la grandeuret la jouissance de la mort Je ne me plierai pas à la force de ce bâtard de Yazīd [le Šāh]

Le jour de 'Āšurā de cette année-là, l'ayatollah Khomeiny prononça un dis- cours hostile au pouvoir depuis l'enceinte de la madrasa Faydịya ${ }^{24}$ de Qom. Il fut arrêté et emprisonné, après quoi des affrontements sanglants opposèrent manifestants et forces de l'ordre. Les victimes parmi les premiers furent aussitôt assimilées aux martyrs de Karbala, ce qui donna lieu à une politisation accrue de la poésie élégiaque. Sur ce processus d'évolution du genre à la période révolutionnaire, les témoignages de certains célèbres chantres d'élégies sont particulièrement intéressants. Ils montrent comment les directives

21 Hisām-Mazāhirī, Risāna-yi šsie eh, 169.

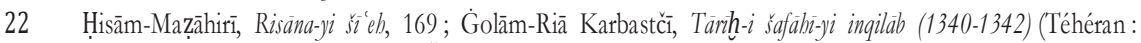
Markaz-iasnād-iinqilāb-iislāmīi,1380Š/2002),vol.2,273-274.

23 Hisām-Mazāhirī, Risāna-yiš̌̀ ể, 170.

24 Lune desécoles religieuses les plus importantes de la ville de Qom, baptisée d'après le théologien, traditionniste et philosopheMuhsinal-Fayḍal-Kāšānī(m.1091/1680). 
du clergé incitaient l'insertion de propos politiques et révolutionnaires dans les poésies rituelles de Muharram ${ }^{25}$.Envoicideuxexemples ${ }^{26}$ :

Ô 'Abbās le beau ! Ô l'échanson de Karbala!

Quel malheur! Quel malheur!

Ses deux mains ont été arrachées

«Par Dieu si vous coupez ma main droite ${ }^{27} \ldots$

Il est temps de te soutenir, ô notre maitre Khomeiny

Ô habitants du monde, Dieu est grand

C'estjour de soulèvement, jour de révolution

Ce n'est pas le seul manque de l'eau à Karbala

Mais le manque de justice, le manque de vertu

Levrai triomphera du faux

Les poésies chantées dans les bay'at (confréries religieuses) révolutionnaires au cours de ces années ne sont plus de purs martīya ou élégies, mais des hymnes révoltés et exaltés, mêlant les figures du drame du passé et les événements du présent. Les leaders shi'ites, intellectuels comme religieux (mentionnons l'ayatollah Murtadāā Muțahharī (1919-1979) et l'intellectuel shì ite 'Alī Šarī' atī (19331977) comme les représentants des deux tendances) n’hésitent plus à mépriserouvertementlesrituels pacifistes du shi ismedoloriste, pourinter- préter le mouvement del'imam Ḥusayn dans le sens d'un shi ismepolitique, activiste etrévolutionnaire.

La victoire de la révolution en 1979, pour les religieux engagés, confirme la splendeur «du sang contre l'épée», la vérité du mouvement de Husayn, la force de la foi shi ite en acte. L'épopée de Karbala s'intègredésormais dansla vie quotidienne du peuple révolutionnaire. La guerre contre l'Irak, déclenchée juste un an après la révolution en 1980, accentue encore cette fusion. Karbala et 'Ášūrā deviennent, huitannées durant, des réalités présentes et palpables. Ainsi, sur les fronts de guerres, les révolutionnaires exaltés revivent sans cesse

25 D'après les souvenirs du chantre Islāmī, ces insertions ne se faisaient pas facilement, elles suscitaient beaucoup d'inquiétude chez les croyants issus des milieux traditionnels, les- quels «faisaient jurerleschantres devantleCoran pourqu'ils récitent aussi des poésies anciennes». Entretien réalisé par Faqīha-Haqqāni en 2005, cité dans HisāmMaẓāhirī, Risāna-yi šì è h,178.

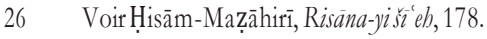

27 Célèbre phrase attribuée à 'Abbās, demi-frère de Husayn, tombé à Karbala. Lors de la bataille,ilaurait dit: «Par Dieu, si vous coupez ma main droite, je suivrai encore ma reli- gion et soutiendrai mon imam, le petit fils pur et honnête [du Prophète] »: Ibn Šahrāšūb Māzandarānī, Manäqib All Abi Țalib (Qom: Intišārāṭt-i 'Allāma, 1338 Š/1959), vol.3,256. 
la passion de leur Imam et de ses compagnons. L'Iran crée et habite son propre Karbala. Layatollah Khomeiny, dans ses discours, compare constamment la situation de l'Iran avec celles du drame de 'Āshūrā dont la littérature envahit l'espace public et les discours: «'Husayn, Ḥusayn' est notre slogan, le martyre est notre fierté » (est un des slogans répétés dans les manifestations politiques durant cette période). Le Karbala historique, situé juste de l'autre côté de la frontière, sur le territoire de l'ennemi, n'est pas oublié, et l'on assimile volontiers le chef irakien Saddam Hussein au calife omeyyade Yazīd avec des expressions comme Saddām YaZid-iKäfir ( «Saddam, l’infidèle Yazīd») 28.

Durant ces huit années de combats et de deuil permanent, les voix de quelques célèbres chantres, appelés chantres révolutionnaires, comme Șādiq Āhangarān, Gulām- 'Alī Kuwaytī-Pūr et Husayn Fahrī transposent les élégiesen mémoirede Karbalaaux deuilsdes soldats etauxautres martyrs de la guerre en cours, invitant les jeunes à rejoindre Husayn. Ils chantent sur le front de guerre, mais leurs voix sont aussi diffusées quotidiennement à l'arrière-front, dans tous les lieux publics, les rues, les écoles, etc.:

Tournez vos visages vers la Ka 'ba des cœurs

Tournez vos visages vers le tombeau du Maitre ('Imam Ḥusayn)

Ô compagnons, faites une nouvelle attaque! Sur vous, pèlerins de Karbala

Sur vous, voyageurs de la voie des prophètes

Quesoitl'admirationdel'espritdeDieu(Ruh-Allāh, prénomdeKhomeiny) Ḥusayn !...

LebeaunomdeHusaynestvotreinvocation(zi $i k r)$ Voirlevisage

de Husaynestvotreespérance (Chanté parKuwaytī-Pūr)

ÔarméeduMahdī,prépare-toipouruncombatimpitoyable Parla passion de

voir Ḥusayn

Tous les cœurs sont ravis

Ce désert est couvert des amoureux de Karbala (Chanté par

Āhangarān)

28 Nous avons développé ce rapport dans un autre article : Sepideh Parsapajouh, «Religiosités entre étatisation et réappropriation populaire. Les cérémonies d'Âshurâ en Iran", dans Simona Tersigni, Claire Vincent-Mory et Marie-Claire Willem (dir.), Appartenances in-désirables. Le religieux au prisme de l'ethnicisation et de la racisation (Collection IntersectionS, Paris: Petra 2019), 175-195. 
Au sein des grandes villes les plus politisés, on tend à oublier l'Imam Ḥusayn historique, soit en l'incarnantau présent, soit en le considérant non pas mort, mais vivant et témoignant. C'est lui qui veille et surveille, lui qui peut inter- venir à tout moment. Les célébrations permettent l'exaltation sacrificielle des pulsions de mort, produisant des chants et des déplorations qui n'obéissent plus à aucune convenance. Tout sepasse comme si, pour surmonter la peur, le chagrin et la souffrance, on devait les renier, louer la mort et mépriser la vie. Même au sein des confréries religieuses (bay'at) traditionnelles, la composition des élégies funèbres en mémoire de Karbala se relâche. La pratique de l'invocation gagne en importance au détriment de la lamentation ${ }^{29}$. L'Imam Husayn n'est plus pleuré mais imploré, appelé à l'aide à travers des pratiques appelées tawassul et tawakkul (demande d'intercession, déclaration de remise confiante à Dieu).

Après la fin de la guerre et la mort de l'ayatollah Khomeiny, sous la présidence de Hāshimī Rafsandjānī (1989-1997) et ses politiques de reconstruction, la société se détache rapidement d'une ambiance de deuil permanent. Les discours et les pratiques politiques, économiques et même religieux, tendent au pragmatisme. L'union sacrée du peuple laisse la place à une recherche d'identités multiples. Les groupes sociaux commencentà revendiquerleurs différences. La nouvelle génération prend largement ses distances avec le pathos du martyre et le radicalisme politique ${ }^{30}$. Ces changements se reflètent clairement dans les rituels de 'Ášūrā, qui ne disparaissent pas du paysage public, mais retournent progressivement à des formes rituelles et des thèmes traditionnels.

Durant la même décennie (1990), d'anciens combattants volontaires, parti- sans convaincus de l'ayatollah Khomeiny, trouvent difficilement à s'adapterà cettenouvelle société. Déçus parle passage d'unsocialismespiritueletégalitaire à un capitalisme matérialiste, et se sentant souvent trahis, ils prennent peu à peu leurs distances avec le pouvoir politique et la religion institutionnelle, se replient dans la dévotion pour les imams shi ites, rendus à leur sacralité, ou dansune forme de douleur pour leurs compagnonsmartyrs. Cesanciens com- battants commencentà encourager, voire à formerdejeunes hommes à l'art poétique et au chantélégiaque. À lafindes années 1990etau débutdes années 2000, de nouveaux chantres sortis de ces milieux deviennent de véritables

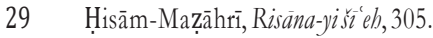

30 Farhad Khosrokhavar, Les nowveaux martyrs d'Allab (Paris: Flammarion, 2003); Sepideh Parsapajouh, «Les valeursen cause: crise de lidéologie et crise de la transmission dans la société iranienne depuis la révolution 1979», Archives des sciencessociales des religions 166 (2014) :243-268. 
«idoles» auprès d'un large public de jeunes croyants de la classe populaire, pour qui la musique et les chansons non religieuses sontconsidéréescomme un péché (g̈inä31).

Dansles naw has de ces nouveaux chantres apparusdanslesannées2000, à la différence des chants des années de la guerre, les paroles sont dénuées des références politiques ou idéologiques modernes. Ils défendent très ouvertement la prééminence de la passion sur la raison, que ce soit dans les actes ou dans les paroles. Leur large public est composé d'hommes et de femmes, bien que seuls les hommes aient le droit d'assister à leurs performances ${ }^{32}$. Tous semblent désireux d'oublier l'idéologie et les douleurs engendrées par elle durant la décennie traversée, comme pour retrouver leur foi dans le shi' isme originel, quiétiste et non politique ${ }^{33}$.

Ces chantres sont des hommes au tempérament manifestement exalté, qui expriment dans leurs textes etleurs attitudes un amourinconditionnel pour les imams. Cet amour s'identifie volontiers à la folie dans des expressions revendiquant la bassesse, la honte et le scandale, comme dans l'ancienne tradi- tion mystique des «gens du blâme» (malämāti). Ils se nomment eux-mêmes, par exemple: «le mendiant de 'Abbās» (gadä-yi 'Abbās), «le maitre des fous» (šayh hal-mağaniñn), «le chien dela maison de

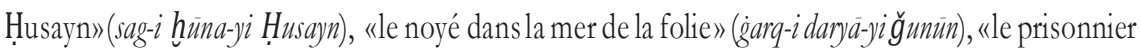
des boucles de cheveux de 'Abbas», ou plus simplement «livre» (mast) ou «le malade» (bimär). Leurs poèmes fontl'éloge de la beauté du visage des imams, de leurs yeux, de leurs sourcils, de leurs cheveux, mais encore de leur corps, de leur taille, qu'ils décrivent en détails. Là où se tiennent leurs performances, des foules d'hommes paraissent en transe, témoignant de paroles et d'actions déchainées:

Situ n'as pas encore vu de fous

Nous voilà, on nous appelle les fous

Moi aussi j’étais sage au début

31 Ginā est un terme arabe signifiant un chant dont la beauté transforme l'état émotion- nel du chanteur et celui de l'auditeur. Il désigne aussi une pratique collective de chant chez les soufis, condamnée comme «innovation blâmable» (bid'a) par de nombreux juristes-théologiens. Au sujet des débats concernant le problème de gināa pendant l'époque safavide, voir Ğa fariyān, "Ihtilāaf nazar-i 'ulamā dar mas'ala-yi ginā dar dawra-yi Safawiyya », (Divergences de vues des savants au sujet du ginà à l'épode safavide) Mağäla-yipažzūhišva haWZah, $\mathrm{n}^{\circ} 3$ (1379 S $/ 2000$ ).

32 Lesfemmesregardentlesfilms decesperformancesouécoutentlesenregistrements.

33 Sur ce point, voir Mohammad Ali Amir-Moezzi, Le guide divin dans le shî isme originel. Aux sources de l'ésotérisme en islam (Paris: Verdier, 1992), 303-335; Idem, La prewve de Dieu.Lamystiqueshi' iteàtraversl'cuvredeKulaynîIXe-Xe siècle(Paris:Cerf, 2018),53-70. 
Mais ton amour m'a rendu fou

M'a exclu d'un coup de la cité des sages

On nous appelle les fous

Pour avoir commis le crime d'êtreamoureux de toi

(Chanté parMuḥammad-ǦawādZ̄ākir)

Toutes les nuits je rêve de Hiusayn et cela merend fou

Les beauxyeux de 'Abbās ont ravi mon cœur

Il a les sourcils arqués, le regardpleinde bonté

Un visage céleste

Tu es beau comme la lune, tu es la fierté de la terre

Tout mon monde est toi seul Husayn, tout mon destin, toi seul Ḥusayn

Toute la beauté, toi seul Ḥusayn, toute la grâce,toi seul Ḥusayn

Mon maitre, toi seul Ḥusayn, mon seigneur, toi seul Ḥusayn

Le cœur est le lieu de manifestation de ta divinité

La Ka 'ba est ton pèlerin à Karbala jusqu'au jour de la Résurrection

Ta soif fait une montagne de feu dans mon cœur,

Que mon cœur soit ton feu éclatant

Les chantres de ce type ne cessent depuis de se multiplier, attirant toujours plus de jeunes gens. Certains d'entre eux se heurtentà de violentes critiques et même à des dénonciations de la part des représentants de la religion institutionnelle, reprenantcontre euxlevieux chefd'accusation de gulüw («exagération» ou «extrémisme», en particulier dans la vénération des imams). Les discours des autorités officielles etdes institutions politiques n'hésitent pas à stigmatiser un phénomène pathologique et déviant. Quant aux laïcs et aux séculiers, ils assimilent ces chantres à des chanteurs de «soirées techno » ou de « soirée ecstasy» camouflés sous un masque religieux ${ }^{34}$.

Nous pouvons suggérer que cette extraordinaire survivance et vivacité de la poésie élégiaque, à travers l'histoire religieuse et politique du shi isme en Iran, correspond à un fond anthropologique déjà connu d'Aristote quand dans sa Poétique, il donnait pour fonction à la tragédie de permettre la catharsis des passions de pitié et de colère35. Dans la tragédie, l'imitation (mimésis) de la souffrance et de la mort permet le transfert et la libération des affects. On sait que la notion aristotélicienne de catharsis a pu se traduire et s'interpréter tantôt comme une purgation, en un sens médical, et tantôt comme une purification, en un sens moral. Comment pouvons-nous l'interpréter s'agissant du martīya shi' ite ?

$34 \quad$ Ces dynamiques ont pris encore de nouvelles formes ces dernières années, que nous n'avons pas intégrées dans cet article.

35 Aristote, Poétique, trad. fr.Jean Hardy (Paris: Gallimard,1996), 1449b, 87. 
D'un point de vue extérieur, la première interprétation de la catharsis semble bien s'appliquer aux acteurs de ce phénomène de société. Ici, il s'agirait d'une catharsis au sens freudien, une décharge émotionnelle liée à une série de traumatismes collectifs, une libération spontanée du refoulement accompagnant une certaine prise de conscience ${ }^{36}$. Le martiya pourrait être une forme shi ite de cette thérapie universelle du mal subi, intégrée danslamémoirecollective et minoritaire par la poésie.

Mais d'un point de vue intérieur, pour nos acteurs shi ites, l'expérience du martīya est plutôt une forme de purification religieuse (tathiri), liée à un état de ravissement et d'amour exalté qui élève l'âme du poète-chantreet celle de l'interlocuteur-auditeur pour les rapprocher de l'Imam, " face de Dieu tournée vers l'homme » selon les termes d'Henry Corbin ${ }^{37}$. Les chantres de la nouvelle vague, décrits plus haut, recherchent et endossent explicite- ment ces états. Citons par exemple Muḥammad-Ǧawād Żākir (1977-2006) : «Je suis animé parl'amour (ǐş $\left.{ }^{38}\right)$ desimams et le ravissement (šurr. Celan'arien avoirniavecles préceptes religieux, ni avecles traités pratiques des marğ $a^{\prime}-i$ taqlid $\rangle^{39}$. L'acteurdelapratique esticianimé parl'amour (hubb) del'imam et, à travers cette pratique, s'acquitte de l'obligation shi ite de tawalla' ('amour des imams) qui constitue presque la moitié de son acte de croire. Selon un hadit rapporté de l'Imam Șādiq, comme on lui demandait si l'amour (ḥubb) et la haine (bugig) faisaientpartie de la foi (imän) (ou dans une autre version: de la religion, dīn), il répondit: « La foi (ou: la religion) est-elle autre chose

36 ElisabethRoudinescoetMichelPlon,Dictionnairedelapsychanalyse(Paris:Fayard,coll. «La Pochothèque», 1997), 251.

37 Henry Corbin, Facede Dieu, face de l'bomme. Herméneutique et soufisme(Paris: Entrelacs, 2008 (1ère éd. 1983)). En Iran et chez les locuteurs persans aussi, l'expression wajh Alläh (face de Dieu) pour parler des imams est très courante.

38 Le terme išq (arabe 'išq) a une connotation très forte, équivalente de «passion», avec parfois un sens mystiquemais le plus souvent un sens charnel. Moḥammad Șadr-Zāda écrit: «Le prophète et les imams n’ont pas utilisé le terme

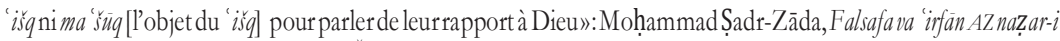
isläm (Téhéran : Rušanāyīi Mihr, 1390 Š/2011), 39-40. Le terme le plus souvent utilisé dans les textes arabes pour parlerdel'amouresthubb, signifiant aussil'amitié.

39 Le marğa al-taqlid (littéralement «source d'imitation») est l'autorité religieuse majeure du shi' isme moderne, dont les simples croyants appelés muqallidūn (en persan muqal- lidān) doivent suivre les directives (voir Hisām-Maẓāhirī, Risanna-yi šì eh, chapitre 6). Pour retrouverces propos: http:// zakerzaker.blogfa.com/category/6. 
quel'amour etla haine?» $»^{40}$. Etcet autre ḥaditattribué au huitièmeimam 'Alī al-Riḍā (m. 203/218) : «La perfection de la religion est l'amour envers nous [les imams] et la haine envers nos ennemis ${ }^{41}$.

De cette perfection de la foi shi ite, si la dimension de l'amour (ḥubb et tamwalä) est suffisamment assumée par les pratiques développées autour de lapoésieélégiaque,qu'enest-ilalorsde sa seconde dimension, celledela haine (bugiz et tabarrä) ? Par quelles expressions rituelles, gestuelles et langagières, se trouve-t-elle assumée dans la religion populaire shi' ite?

\section{II}

Dans la tradition iranienne shi ite, différentes pratiques religieuses prennent en charge cette «haine sacrée » à l'égard des ennemis des «gens de la Sainte Famille du Prophète» (abl al-bayt). Je mentionnerai d'abord la lecture quasi-quotidienne de textes sacrés, attribués aux imams, contenant des malédictions $\left(l a^{\prime} n\right)$ adressées à leurs adversaires. Le plus couramment récité est la Ziyārat 'Ā̌suruà («[nvocation] pour la visite de 'Ášrürà)». Sa version la plus ancienne est attribuée au cinquième imam Muḥammad al-Bāqir (m. ca 114/732) et rapportée dans le Kämil al-Ziyärät d'Ibn Qulūya al-Qummī (IVe/Xe siècle). Il rappelle avecuneintense ferveur lesinjustices subies parles membres dela Sainte Famille du Prophète (ablal-bayt) et maudit à de nombreuses reprises les auteurs de ces injustices, ennemis de cette Famille - qu'il s'agisse d'individus comme 'Ubayd Allāh b. Ziyād, Šimr, 'Umar b. Sa' det Yazìd ou de tribus entières comme les Āl-i Ziyād, les Āl-i Marwān et les Banū Ummaya. Le mot la n («malédiction», «maudit») est répété pas moins dequatorze fois dansle texte. En voici un extrait traduit:

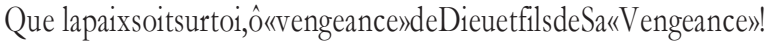

Paix surtoi, ô vengeance et revendicateur devengeance!

Ô Abū 'Abdallāh (Husayn), le malheur de ta perte est immense, cette épreuve est terrible et difficile à supporter pour nous et pour tous les gens de l'Islam.

40 Muḥammad b. Yá qūb al-Kulaynī, Ușül al-Käfí, éd. et trad. pers. Ṣādiq Ḥasan-Zāda (Qom : Âl-i Muhamamad, 1387 Š/2008-09), vol. 2, 125; Mağlisī, Bịhạr al-anwär, vol. 64, 52, vol. 65,63.

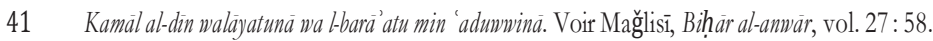


Le malheur de ta perte est immense, cette épreuve est terrible et difficile à supporter également pour les gens des cieux.

Que Dieumaudissedoncunpeuplequiaédifiélesfondementsdel'injusticeetdel'oppression survous, GensdelaMaison(abl-al-bayt).

QueDieu maudisse un peuple qui vous a écartés de votre position et vous a confisqué les rangs dans lesquels Dieuvousavaitplacés.

Que Dieu maudisse un peuple qui vous a assassinés et qu'Il maudisse ceux qui lui ont préparé leterrain pour vous combattre.

Abū 'Abdallāh (Husayn), je suis en paix avec ceux qui sont en paix avec vous et en guerre contre ceux qui sont en guerre contre vous, jusqu'au Jour de la Résurrection.

Que Dieu maudisseles Āl-i Ziyād etles Āl-i Marwān.

Qu'Allah maudisse tousles Banū Umayya sans exception.

QueDieumaudisseIbnMarğāna.

QueDieumaudisse 'Umarb.Sa'd.Que Dieu maudisseŠimr.

Que Dieu maudisse un peuple qui est monté en selle, qui a bridé ses chevaux et qui s'est préparé en vue de te combattre.

Je demande donc à Dieu, qui t’a honoré de ton rang et par toi m’a honoré, qu'Il m'accorde la chance de te venger aux côtés d'un Imam victorieux descendant des Gens de la Maison de Muhammad,quelaprièresoitsur lui et les siens.

Ô Abū 'Abdallāh (Ḥusayn), je demande à être rapproché de Dieu, de Son Envoyé, du Commandeur des croyants ('Imam 'Alī), de Fāțima, de Hasan et de toi, parmon amourpour toi, parmon rejet et mon désaveu de ceux quiontposélesfondations devotremalheur, ontbâtileur édifice, et n'ont cessé de poursuivre leur injustice et leur oppression contre vous et vos partisans $(\ldots)$

Je m’arrêterai plus longuement sur la tradition dite du 'Umar-koši («le meurtre de 'Umar», en référence audeuxièmecalife 'Umarb.al-Hुatțāb), Aïdal-Zahrā' (fête de Zahrāa', autre nom de Fātịma), Farhat al-

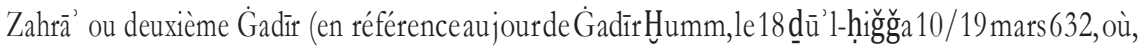
d'après les shi ites, le Prophète désigna 'Alī comme son successeur). Cette pratique a cours lors d'une période située entre le 9 et le 17 du mois arabe de rabî' al-awwal. Il s'agit de réunions consacrées à la malédiction rituelle des ennemis des imams, dont les participants sont des croyants appartenant surtout aux couches populaires. Son contenu, mettant en scène l'humiliation de l'ennemi par le geste et la parole, relève largement de la satire (hağw), qui dans l'histoire de la poésie arabe est un genre aussi ancien que l'élégie. À la différence de la lecture des textes pieux contenant la malédiction des ennemis, très 
répandue, ces fêtes sont méprisées, stigmatisées par la religion institutionnelle et aujourd'hui interdites par la loi iranienne. Toutefois, elles sont célébrées avec ardeur chaque année, de manière clandestine,et semblentencore plus répandues aujourd'hui qu'au cours des dernières décennies.

D'après certaines sources, cette pratique trouverait ses racines dans des traditions de la Perse antique nommées Muğ-koši (Meurtre du mage) ${ }^{42}$, effectuées chaque année pour la célébration de lanniversaire de la victoire de Darius le Grand contre le Gaumata, un mage qui, d'après les textes antiques, lui avait volé son droit de succession à la mort de Cyrus. Darius aurait réussi à tuer Gaumata en 522 avant l’ère commune et à reconquérir la couronne pour réta- blir la justice ${ }^{43}$. Cet anniversaire était loccasion de manifestations joyeuses accompagnées d'importantes violences contre les mages qui, de ce fait, se cachaient parpeur de la profanation, des humiliations et des agressions ${ }^{4}$.

Dans le shi isme populaire iranien, les cérémonies de 'Umar-koši ont pris des formes différentes au cours de l'histoire moderne, se plaçant entre d'un côté la prohibition officielle et de l'autre, les célébrations effectives de ces cérémonies. Ce qui s'y exprime toujours, à travers des ensembles de gestes et de paroles satiriques ritualisés, c'estla haine contre les ennemis des ablal-bayt, l'acquittement de l'obligation du tabarräa', symétrique de celle du tawallä 45 .

Nous manquons d’informations précises sur l'ancienneté de la fête shi ite de 'Umar-koši, mais il semble qu'elle fut mise en place et même encouragée en Iran à lépoque de la dynastie safavide (9061135/1501-1725) dans un climat d'hostilité contre l'empire ottoman sunnite. La seule source écrite légitimant ce rituel est un court passage du Bihäar al-anwär, l'encyclopédie de hadiț imamites due au traditionniste Muḥammad Bāqir al-Mağlisī (m. 1111/1699) 46. Durant l'époque Qàjāàr et Pahlavi (XVIIIe-XXe siècles), cette fête était très courante, sous des formes différentes, et se déroulait parfois dans les espaces publics, entrainant parfois de graves violences contre les communautés sunnites. Après la révolution islamique, alors que la politique encourageait l'unité (wahdat) entre shi ites et sunnites, surtout à la suite d'une fatwa de l'ayatollah Khomeiny, ces célébrations ont été officiellement interdites par la loi ${ }^{47}$, et les

42 Voir Don Rubin, Chua Soo Pong, Ravi Chaturvedi, Ramendu Majundar et Minoru Tanokura, The World Encyclopedia of Contemporary Theatre: Asia/ Pacific (Abingdon: Routledge, 2001),192.

43 Pierre Briant, "Gaumāta ", Encyclopaedia Iranica, X.3, 333-335. Version revue accessible en ligne : http://www.iranicaonline.org/articles/gaumata.

44 Walter Bruno Henning, «The Murder of the Magi», Joumal of the Royal Asiatic Society, 76 (1944), 133-144.

45 Surces deux concepts dansle shi' isme, voir Amir-Moezzi, Lapreuvede Dien, 46-47.

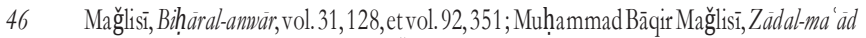
(Téhéran: Intišàrāt-i Islāmīya, 1370 Š/1991-92), 258.

47 Lamesure futpriseetappliquée parleministre enexerciceàl'époque,Muḥtašami-Pūr. 
forces de sécurité veillent encore aujourd'hui au respect de cette interdiction. Ces cérémonies se tiennent secrètement dans des réunions fermées, et leurs participants viennent sur invitations privées.

Quelle est l'occasion historique précise de cette célébration? Qui est le 'Umar personnage principal du rituel, cible des malédictions et humiliations symboliques ? En réalité, on ne sait plus très bien à quel événement correspond ce jour du $9 \mathrm{rabī}^{-}$al-awwal. La croyance populaire veut qu'il s'agisse de l'anni- versaire de l'assassinat de 'Umar b. al-Hुatțāb. Pourtant, d'après les documents historiques, le

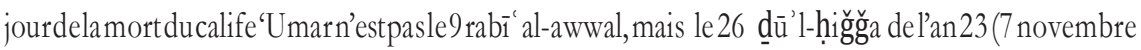
644) 48. Seullepassage déjà évoqué du Biḥäral-anwärde Mağlisī donnela datedu 9 rabî̀ al-awwal pour celle del'assassinat de 'Umar b. al-Hatțāo ${ }^{49}$.

Rappelons que pour les shi'ites, 'Umar est considéré comme le premier traitre parmi les compagnons du Prophète, responsable d'avoir écarté l'imam 'Alīdu califat, d'avoirprivésafilleFātima de sondroità l'héritage surl'oasis de Fadak, et même d'avoir causé sa mort, avec celle de l'enfant qu'elle portait (déjà appelé Muhsin), dansl'attaque de sa maison, quelques mois après la mort du Prophète'Umar, furieux que 'Alīaitrefusé de prêter allégeance à Abū Bakr, aurait ordonné à son homme de lige Qunfud d'agresser Fātima. Douze ans plus tard, après avoir lui-même exercé le califat, 'Umar était assassiné parun certain Abū Lu' lu' ou Pīrūz Nahāvandī, commel'appellentles Iraniens. La tombe de ce dernier, aux alentours de la ville de Kāšān en Iran, fut longtemps un objet de vénération et un lieu de célébration du rituel de 'Umar-koši. Sur une décision de l'État, ce mausolée a été définitivement fermé au public en 1997 puis transformé en siège de basiğs, les «mobilisés » défenseurs du République islamique.

D'après une autre interprétation savante, que l'on retrouve d'ailleurs dans un autre ouvrage d'alMağlisī, le Zädal-ma äd (Le viatique du Retour), le 'Umar de cette cérémonie n'est pas le deuxième calife mais une autre figure historique également détestée des shi'ites, à savoir 'Umar b. Sa'd, commandant de l'armée de Yazỉd 1erlors dela bataille de Karbala (680); c'estluiqui donna l'ordre de mettre à mort l'imam Husayn et ses compagnons ${ }^{50}$. Cet homme, d'après les sources historiques, fut décapité six ans après le drame de Karbala par Muhtār al-Taqafì (m. 67/287), chef d'un mouvement de révolte 'alide visant à venger la mort de Hiusayn. 'Umar b. Sa'd fait partie de ces individus auxquels,

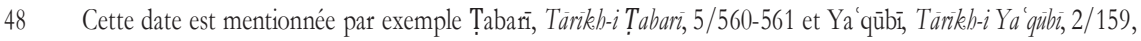

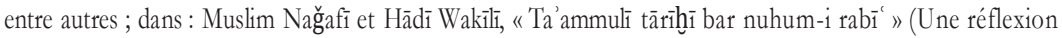
historique sur le neuvième jour du mois de Rabî'),Mutäla át-iislämi:Tärikkbva farbang, 84-85(1389 Š /2010): 51-82.

49 Mağlisī, Bihhäral-anwär, vol. 92,351.

50 Mağlisì, Zä̀d al-ma'àd, 412. 
depuis des siècles, les shi ites adressent systématiquement des malédictions lors deleurs prières. C'est notammentlecas, nousl'avonsvu, danslefameux texte de la Ziyärat 'Ā̌sürā.

D'autrepart,le9 rabî'al-awwal, danslecalendrier shi ite, estle jourdu début de l'imamat de l'imam caché, correspondant au lendemain de la mort du onzième imam Ḥasan al-'Askarī (m. 260 / 874). C'est pourquoi, parallèlement à l'interdiction des cérémonies de 'Umar-koši à partir de 1980, la République islamique d'Iran a désigné cette même période du 10 au $17 \mathrm{rabî}^{-1}$ al-awwal comme la semaine de l'unité (wahdat) entre shi ites et sunnites ${ }^{51}$, justifiée par la commémoration de la joie du début de l'imamat de l'imam caché. On peut voir là, justement, une volonté de refouler le tabarrà', l'expression sacrale de la haine à l'égard des ennemis des imams. En même temps, le glissement est signifiant: 'Umarreprésentela figue dumalquele shi isme a subiau coursde sonhistoireminoritaire, etle Mahdi celle de la promesse d'un rétablissement universel de la justice. Les célébrations festives sont ainsi encouragées et le rituel de 'Umar-koši trouve précisément là l'occasion de s'exercer, camouflé sous les réjouissances collectives officielles. Dans les manifestations de joie extrêmes observables en cette période, il est bien difficile de distinguer la part de la haine pour 'Umar etcellede lajoie pourl'imamatdu Mahdi.

À cette occasion unique et dans ces lieux discrets, comme me l'ont appris de nombreux entretiens, c'est tout l'ordre de la bienséance qui se renverse ; les manières vestimentaires, les comportements, les expressions physiques et orales deviennent volontiers obscènes; la couleur rouge domine, contre le noir et le vert habituellement valorisés; des danses sont accompagnées de musiquelégère et superficielle, dechants frivoles relevant de la pratique interdite ou répréhensible du g̈inä; les plaisanteries légères, les propos satiriques et les rires sans retenue s'imposent, transgressant les valeurs morales et esthétiques du temps ordinaire. Les paroles et les gestes montent en puissance jusqu'à, selonles termes de mesinterlocuteurs, «cassertoutesleslimites», «faire rougirl'observateur extérieur», «comme s'il n'y avait plus de frein», «comme si le monde était détourné», «comme si l’on ne maîtrisait plus rien». Certains disent avoirressentiun tel «danger»dû au désordre ambiant qu'ils renoncèrentà participer à ces cérémonies ${ }^{52}$. Certaines personnes s'y pré- sentent déguisées ou masquées afin de ne pas être reconnues. Les mises en scènes insistent particulièrement sur les rapports sexuels mimés et simulés. Toutefois, et c'est peut-être tout ce qui reste de l'ordre moral, la séparation

51 Le17 rabī' al-awwal est également, pour les shi ites, l'anniversaire de la naissance du Prophète.

52 Mary Douglas, De la souillure. Essai sur les notions de pollution et de tabou, trad. fr. Anne Guérin(Paris: Maspero, 1971). 
des sexes demeure: les femmes sont entre elles, les hommes entre eux. Mais dans chaque groupe, on joue parfois à renverser les rôles avec «des femmes quijouentle rôle del'homme»et «deshommesqui font la femme ». L’interdit, le tabou, la notion même de péché, semblent avoir perdu leur poids normatif quand il s'agit de fêterla mort des ennemis des imams.

Le rituel se cristallise d'abord autour d'une marionnette préparée avec beaucoup de soins et d'investissementéconomique. Cette figurine représente 'Umar-qu'ils'agissede 'Umarb.al-Huatțāboude 'Umar b. Sa'd importe peu pour les participants. Chez les femmes comme chez les hommes, cette incarnation dela figuremasculinedel'ennemiprend pourtantle corpsd'unefemme, lequel devient l'objet d'humiliations et d'agressions. Par des gestes et des chants déshonorants, on maudit la marionnette. Puis les figures historiques connues comme ennemies des abl al-bayt sont longuement énumérées et maudites. Au fur et à mesure, les malédictions montent en puissance, les participants perdent toute retenue, un enthousiasme quasi-agressif s'empare de toute l'assemblée.

Conscients du caractère transgressif de ces pratiques, les acteurs affirment pour les justifier que ce temps est une période de raf al-qalam, littéralement de «suspension de la plume»: une période durant laquelle les anges du Jugement dernier cessent de noter les actes des hommes; les péchés ne sont donc pluscomptabilisés etlesactes sontneutralisés, tout devenantainsi per- mis. Cescroyants se

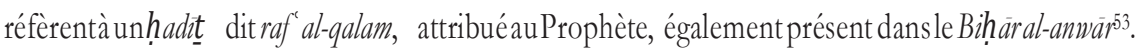
Envoicile texte: «J'ai demandé aux anges qu'ils cessent de noter les actes de tous les gens pendant trois jours, et n'enregistrent plus rien de leurs péchés $\aleph^{54}$. Nombre d'autorités shi'ites rejettent l'authenticité de cette tradition et/ ou soninterprétation licencieuse ${ }^{55}$,

53 La source originaire de ce hadițt, selon Mağlisī quil'associe au 9 rabî' al-awwal comme jour de la mort de 'Umar (Bihâr al-

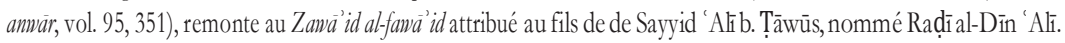
Toutefois, les savants shi ites ne le considèrent pas comme authentique puisqu'il n'apparait pas dans les compilations les plus anciennes de ḥadîț des traditionnistes comme al-Kulaynī, al-Šayh al-Ṣadūq et al-Šayh alȚūsi. L'expression raf' al-qalam est citée dans deux ḥadițs rapportés par al-Šayh al-Ṣadūq(dans 'Uyünahbăral-Riḍa

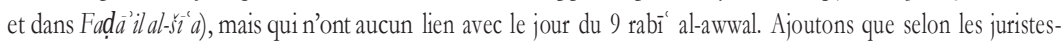
théologiens, l'analyse complète de ce hadit montre d'autres contradictions doctrinales avec cette interprétation populaire, qu'ils jugent invalide.

54 Mağlisī, Bịhäral-anwär, vol. 31:125.

55 La source scripturaire de ce hadit est inconnue et ses chaines de transmission ne vont pas plus loinquele VIe/XIIe ou

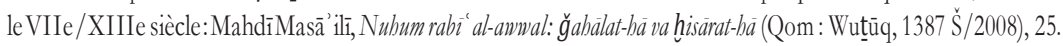
À ce propos voir aussi Ma 'ṣūma Šîrdal et Parwīn Bahārzāda, " Naqud-i sanad-hā va dalālīi-yi riwwāyat-i raf' alqalam ", 'Ulimm-i hadit 22/4, ñ 86 (2017) : 123-146. Parmi ceux qui ont critiqué ce hadidit, nous pou- vons citer les fatwas del'ayatollahNūurîHamadānī, del'ayatollahFāżil Lankarānīet de 
et les savants contemporains refusent généralement toute légitimité scripturaire à ces fêtes. À une quasi-unanimité, les clercs méprisent et réprouvent ces actes considérés comme indécents en s'appuyantsurleversetcoranique 29: 29, censé avoir été révélé au sujet des gens de Luth: « N'est-il pas vrai que vous allez aux garçons, coupez le chemin, vous portez dans vosassemblées au mauvais dessein ?». Pour toute réponse, son peuple dit: ^Amène-nous donc le châtiment de dieu, si tu es tellement véridique $\gg{ }^{56}$.

Cette réprobation vise ainsiles pratiques obscènes effectuées lors de ces cérémonies, mais il faut souligner que la malédiction et l'expression de la haine ne sont pas condamnées en elles-mêmes. Quantà ce mépris des savants pour les pratiques de la religion populaire, il n'est pas récent. On peut mentionner la critique virulente de ce rituel par Qāḍī Nūrallāh Šušstarī, juriste et traditionniste shi ite del'époque safavide, exécuté en Inde en 1119/1610, appelé

«le troisième martyre» (šabid-i tälitit), dans son ouvrage intitulé Mașäib al-nawașịib (Les fléaux des ennemis de 'Ahl $)^{5}$. Toutefois, lon peut se deman- der si cette condamnation ne relève pas, chez cet auteur couramment accusé d'« exagération» (ginlinw), de la tagjya, la dissimulation pieuse d'articles de la foi particulièrement sensibles pour protéger la vie du croyant. À linverse, le discours retentissant contre ces cérémonies de Muhammad Husayn Kāšif al-Gitạā (1294/1877-1373/1953), autorité religieuse majeure (marğa' al-taglid) de la ville de Najaf, n’a rien détonnant de la part de ce partisan inlassable du rapprochement des confessions (tagrib al-madäbib) et de l'union (ittihää) des shi ites et des sunnites, qui introduisit la notion du droit ajusté (figh tațiaii).

Néanmoins, si ce rituel de 'Umar-košì a résistéà toutes les réprobations et interdictions officielles, c'est qu'il doit jouer un rôle essentiel pour les croyants ordinaires, non moins essentiel que celui du martiya et de la commémoration du deuil de l'imam Husayn. Quelle est alors la fonction de cette débauche de joie et de rire satirique? À l'évidence, la satire porte en elle une bonne dose

l'ayatollah Makārim Širāzī, qui ont catégoriquement nié son authenticité. Pour leur part, Sayyid 'Alī Khamenei, le Guide suprême de la République islamique d'Iran, l'ayatollah Mișbāh Yazdī, l'ayatollah Ardabilli et l'ayatollah Bahğat, sans se référer explicitement à ce hadiț, ont prononcé de nombreux avis généraux contre tout ce qui nourrit la division de la communauté musulmane, c'est-à-dire entre shi ites et sunnites, et contre ce qui donne des prétextes aux « ennemis » des shi'ite.

56 LeCoran, trad. J. Berque, 426.

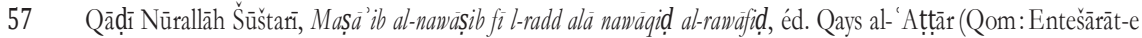

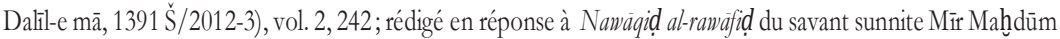
Šarifíquiavait parlé de ces rituels. À propos de ce traité, voir Muhammad Qazwīnī, «Šarḥi-i ahwāl-i Mīr Mah̆dūm Šarifìi, Farbang-i İrä Zamin 1 (1332 Š/1953): 57-69. 
d'agressivité et exprime un sentiment de puissance, de supériorité de la part des rieurs sur le sujet devenu risible parce que dégradé, avili, humilié. D'un point devue freudienencore ${ }^{58}$, le rireetla satire ont pour fonction de causer un soulagement permettant de libérer la pression générée par le contrôle des affects (en l'occurrence celui de la haine, bugig), par le refoulement de certains comportements prohibés par la collectivité (en l'occurrence, dans l'histoire des shi ites, la majorité dominante sunnite). Mais cette appropriation du rire et de la violence symbolique ne va pas de soi. En général, la violence, l'humiliation, la moquerie, le dévoilement et le désordre corporel apparaissent comme des actes foncièrementirrationnelsetdonctabou,contrairesà touteslesnormes sociales. Le shi isme moral et juridique, notamment sous sa forme pratiquée aujourd'hui en Iran, ne fait pas exception; en accord avec la tradition judéo-chrétienne ${ }^{59}$, il considère le rire comme un signe presque démoniaque, du moins une émotion contraire à toute sacralité. L'opinion morale la plus répandue est que le rieur, un peu à l'instar de l'hommeivre, n'est pas maitre de soncorps.

En dépit des interdictions et des réprobations, les croyants ordinaires continuentà rire, se moquer et maudire, chaque annéeà cette occasion com- mémorative dissimulée sous une autre. À ces moments, s'exprime une joie aussi extrême et passionnelle que peut l'être la tristesse lors des commémorations de 'Āshürā'. En transformant pacifiquement la haine de l'ennemi, source du mal, en une forme de violence symbolique, les croyants observent le principe shi' ite de tabarra $a^{-}$en attendant patiemment le rétablissement de la justice finale. Ce rituelapparait biencommele complément pour ainsi dire naturel du martĩya, des lamentations et pleurs accompagnant les expressions de la poésie élégiaque, parlesquelles on s'acquitte du devoir d'amour pour les imams, le tawallä.

\section{III}

Pour finir, ces deux pratiques du martīya et du 'Umar-košiz, conséquences symboliques, à la fois antagonistes et harmonieuses, de la conscience historique du mal chez les shi' ites, peuvent être interprétées ensemble dans le cadre de la théorie du don élaborée par Marcel Mauss. Dans son Essaisurle don paru pour

58 Sigmund Freud, Le mot d'esprit et ses rapports avec linconscient, trad. fr. Marie Bonaparte et M. Nathan (Paris : Gallimard, 1930).

59 Erwan Dianteill, « Rire », dans Régine Azria, Danièle Hervieu-Léger et Dominique Iogna-Prat (éd.), Dictionnaire des faits religienx. Paris: PUF, 2ème édition, 2019, 1178-1189. 
la première fois en 192460, l'anthropologue français montre que dans toutes les civilisations, le don est obligatoirement suivi d'un contre-don (selon des codes préétablis) et queles deux, donetcontre-don, sontarticulés autourdelatriple obligation de «donner, recevoir et rendre», constitutive du lien social. Cela vaut essentiellement pour ce qui est considéré comme bien et comme biens (gestes de bienveillance, cadeaux, valeurs d'usage); mais au-delà des analyses de Mauss lui-même, cela peut valoir aussi, en un sens dérivé, du mal et des maux, qu'il faut aussi savoir, dans certaines circonstances de la vie sociale, donner, recevoir et rendre. Ainsi le rituel du 'Umar-košī, dont la vivacité répond à celui du martiyya, est une manière de rendre symboliquement le mal subi et reçu, non pas tant, comme chez Mauss, pour créer une dépendance qui entrainerait la recréation permanente du lien social - qui serait ici la guerre perpétuelle -, mais plus simplement, et pragmatiquement, pour assurer un équilibre psychique et social au monde des croyants shi' ites dans leur relation toujours ambivalente etconflictuelle avecle monde sunnite.

\section{Bibliographie}

\section{Sourcess}

Aristote. Poétique. Tr. fr. J. Hardy. Paris : Gallimard, 1996.

Le Coran. Essai de traduction par Jacques Berque. Paris : Albin Michel, 2002.

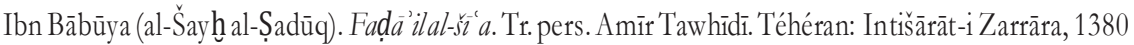
$\check{S} / 2001-02$.

IbnBābūya (al-Šayhąal-Șadūq). 'Uyūnaḩbäral-Ridā.Tr.pers.HamīdRiḍāMustafidet 'Alī-Akbar Ǵaffārī. Téhéran: Našri-i Șadūq, 1373 Š/1994.

Al-Fayḍal-Kāšānī,Muḥsin. Tafsīral-ṣạfi.Éd.SayyidMaḥmūdImāmiyān.2vols.Qom: Dַawīl-qurbā, 1388 $\check{S} / 2009$.

Freud,Sigmund.Lemotd'espritetsesrapportsavecl'inconscient.Tr.Fr.MarieBonaparte et M. Nathan. Paris: Gallimard, 1930.

Al-Ḥillī, Ḥasan b. Sulaymān. al-Muhtașar. Éd. Sayyid 'Alī Ašraf. Nağaf : al-Maṭa a al-ḥaydarīya, 1390/1970.

IbnŠahrāšūbMāzandarānī.Manāqib ĀlAbiṬälib.4vols.Qom:Intišārāt-i'Allāma,1338 Š/1959.

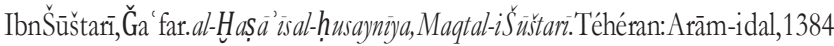
Š/2005-06.

60 Marcel Mauss, Essaisurle don, dans sociologie et anthropologie (Paris: Presses Universi- taires de France, 2012), 143-279. 


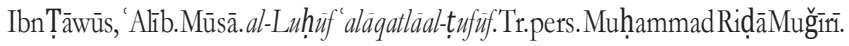

Qom : Baqīyat Allāh, 1390 Š/2011.

Ibn Ṭāwūs, Radị al-Dīn 'Alī. Zawāà id al-fawầi id. Manuscrit inédit, bibliothèque centrale de l'Université de Téhéran 128/1.

Kāšānī, Muhtašam. Diwān. Éd. Akbar Bihdārvand. Téhéran : Intišàrāt-i Nigāh, 1392

$\check{S} / 2013-14$.

Kulaynī,Muḥammadb.Ya'qūb.Ușiülal-Käfi.Éd.et tr.pers.Ṣādiq Ḥasan-Zāda.Qom: Āl-i Muḥammad, 1387 Š/2008-09.

Mağlisī,MuḥammadBāqir.Zädal-Ma'àd.Téhéran:Intišārāt-1islāmiyya,1370Š/1991-92. Mağlisī, Muḥammad Bāạir.

Bihäral-anwär. 110 vols. Téhéran: Matba at al-'Alawī, 1364

Š/ $/ 1985$.

Mas' ūdī, 'Alīb.Husayn.Muriǧg al-dabab(Prairiesd'or).Tr.pers.Abū-l-Qāsim Pāyanda.

Téhéran : Intišārāt-i 'ilmī wa farhangī, 1382 Š/2003-04.

Al-Qummī, Ibn Qulūya. Kämil al-Zivaaraät. Tr. pers. Muḥammad Ǧawād Dihnī Tihrānī.

Téhéran : Payām-i ḥaqq, 1377 Š/1998.

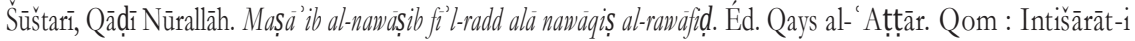
Dalì-i mā, 1391 Š/2012-13.

\section{ÉTUDES}

Aghaie,KamranScott. The MartyrsofKarbala. Shi i SymbolsandRitualsinModern Iran. Seattle: University of Washington Press, 2004.

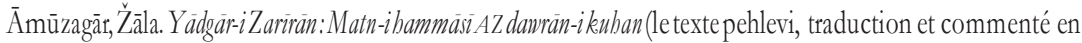
persan). Téhéran: Intišāàāt-i Mu īn, 1393 Š/2014.

Amir-Moezzi, Mohammad Ali. Lapreuve de Dieu. La mystique shi ite àtraversl'auvre de KulaynîIXe-Xesiècle. Paris: Cerf, 2018.

Amir-Moezzi,Mohammad Ali. Leguidedivindansleshî ismeoriginel. Aux sources de l'esotérisme en islam. Paris : Verdier 1992 (rééd. 2006).

Azarandaz, Abbas. "Yadgār-i Zarīrān, namūna-yi az hunar-i šă ìrī-yi ìrāniyān dar dawra-yi miyāna». Zabān-šanāht, (Téhéran: Pažūhašgāh-i 'ulūm-i insānī va muțāla āt-i farhangī) 4.2 (1392 Š/2013-14): $1-24$.

Briant,Pierre.«Gaumāta».DansEncyclopaediaIranica.accèsenligne:https://www iranicaonline.org/articles/gaumata- (Enc. It. X.3,333-335).

Boyce, Mary. "Yāidgār-e Zarīrān ». Dans Encyclopedia Iranica. accès en ligne : http:// www.iranicaonline.org/articles/ayadgar-i-zareran/ (Enc.IrIII.2,128-129).

Calmard, Jean. «Shi i Rituals and Power II. The Consolidation of Safavid Shi' ism: Folklore and Popular Religion ». Dans Safavid Persia. Éd. Charles Melville. London - New York : Pembroke Papers, 1996, 139190. 
Corbin, Henry. Face de Dieu, face de l'bomme. Herméneutique et soufisme. Paris: Entrelacs, 2008 (1ère éd. 1983).

Dandamayev, Muhammad A. "Magophonia ». Dans Encyclopaedia Iranica. Accès en ligne : http://www.iranicaonline.org/articles/magophonia.

Dianteill, Erwan. «Rire». Dans Dictionnaire des faits religieux. Éds. Régine Azria et Danièle Hervieu-Léger. Paris: PressesUniversitaires deFrance, 2010,1100-1102.

Douglas, Mary. De la souillure. Essai surles notions de pollution etde tabou. Tr. fr. Anne Guérin. Paris: Maspero, 1971.

Ğa fariyān, Rasūl. «Ihtilāaf naẒar-i 'ulamāà dar mas'ala-yi goinā dar dawra-yi Safaviyya», (Discussions des oulémas au sujet du problème ginnā de pendant l'épode safavide) Mağala-yipažühish va haWZZah, n 3 (1379 Š/2000).

Henning,WalterBruno.«TheMurderoftheMagi».JournaloftheRoyalAsiaticSociety 76 (1944) : 133-144.

Hisām-Mazāāirī,Muhsin. Risāna-yiš̌̀ a. Téhéran:Šarkat-ičāpvanašrr-ibaynal-milal, 1388 Š/2009.

Karbastčì, Gulām-Riḍā. Tärĭh-i šafähi-yi inqiläb (1340-1342). Téhéran: Markaz-i asnād-i inqilāb-i islamī, vol. II., $1381 \check{S} / 2002$

Khosrokhavar, Farhad. Les nowveaux martyrs d'Allah. Paris : Flammarion, 2003. Masāilī, Mahdī. Nubum rabī al-awwal: ğabälat-bā va hisärat-bā. Qom: Intišārāt-i

Wut̄ūq, 1387 Š/2008.

Massé, Henri. «Poèmes funèbres consacrés aux imâms ». Dans Le shâ isme imâmite. Éd.

Toufic Fahd. Paris : Presses Universitaires de France, 1970, 271-279.

Mauss,Marcel.Essaisurledon.2eéd.F.Weber.Paris:Presses Universitaires deFrance, 2012.

Mervin, Sabrina. «'Ashūrā Rituals, Identity and Politics: A Comparative Approach (Lebanon and India)». Dans The Study of Shi i i Islam:History, Theology andLaw. Éds. Farhad Daftary et Gurdofarid Miskinzoda. Shi i Heritage Series. Londres:

I.B. Tauris in association with the Institute of Ismaili Studies, 2014,507-528.

Mervin, Sabrina. «Les larmes et le sang des shi ites: corps et pratiques rituelles lors des célébrations de 'Âshûrâ (Liban, Syrie)». Revue des mondes musulmans et de la Méditerranée, 113-114 (2006): 153-156.

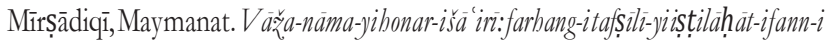
ši r va sabk-bā va maktab-hä-yi ān. Téhéran : Kitāb-i Mahnāz, 1389 Š/2010.

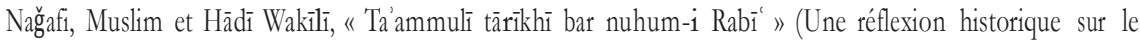
neuvième jour du mois de Rabî'), Mutäla'ät-i islämi: Tärikh va farbang, 84-85 (1389 Ś /2010):51-82.

Parsapajouh, Sepideh. «Les valeurs en cause : crise de l'idéologie et crise de la trans- mission dans la société iranienne depuis la révolution 1979». Arcbives des sciences socialesdes religions 166 (2014): 243-268.

Parsapajouh,Sepideh.Auccurd'unbidonvilleiranien.Paris:Karthala-IFRI,2016.

Parsapajouh, Sepideh. «Religiosités entre étatisation et réappropriation populaire. Les cérémonies d'Ashura en Iran ». Dans Appartenances in-désirables. Le religieux au 
prismedelethnicisationetdela racisation. Éds. Simona Tersigni, Claire Vincent-Mory et Marie-Claire Willem. Collection IntersectionS. Paris: Petra, 2019, 175-195.

Parsapajouh, Sepideh. «Médiation et pouvoirs du texte dans la visite rendue à limām Husayn. Étude anthropologique du contenu et des usages d’un Ziyärat-nämeb shi ite». À paraître.

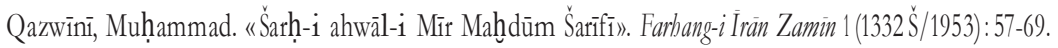

Roudinesco, Elisabeth, et Plon, Michel. Dictionnaire de la psychanalyse. Paris: Fayard, 2011 (1ère éd. 1997).

Rubin, Don, Pong, Chua Soo, Chaturvedi, Ravi, Majundar, Ramendu, and Tanokura, Minoru. The World Encyclopedia of Contemporary Theatre: Asia/Pacific. Abingdon:Routledge, 2001.

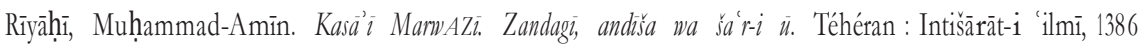
$\check{S} / 2007$.

Șadrzāda, Muḥammad. Falsafa va 'iffän AZ naẒar-i isläm. Téhéran: Rušanāȳīyi Mihr, 1390 Š/2011.

Šìrdal, Ma 'ṣūma et Bahārzāda, Parwīn. «Naqd-i sanad-hā wa dalālī-yi riwāyat-i raf' al-qalam ». 'Ulüm-ihadīt 22/4, nº $86(1396 \check{S} / 2017): 123-146$.

Terrier, Mathieu. Histoire de la sagesse et philosophie shi ite. Paris : Cerf, 2016.

Terrier, Mathieu. «Le combat sacré des vaincus de l'histoire: expérience et représen- tation du jibäad dans le shï̈sme imamite ancien». Journal Asiatique, 305.1 (2017):23-31. 